Yuhui Zhou, Li He* and Wei Gong*

\title{
Effects of zinc acetate and cucurbit[6]uril on PP composites: crystallization behavior, foaming performance and mechanical properties
}

https://doi.org/10.1515/epoly-2018-0107

Received May 23, 2018; accepted July 15, 2018; previously published online August 27, 2018

\begin{abstract}
In this study, polypropylene (PP) foams were prepared with $1.0 \mathrm{wt} \%$ of cucurbit[6]uril (Q[6]), zinc acetate (Zn(Ac) $\left.)_{2}\right), \mathrm{Zn@Q[6]} \mathrm{(a} \mathrm{supramolecular} \mathrm{compound} \mathrm{syn-}$ thesized from Q[6] and $\mathrm{Zn}(\mathrm{Ac})_{2}$ ), or a mixture of $\mathrm{Zn}(\mathrm{Ac})_{2}$ and $\mathrm{Q}[6]$ (weight ratio of 1:1) through injection molding in the presence of a chemical blowing agent, azodicarbonamide. The effect of the additions on the crystallization behavior and foaming performance of $\mathrm{PP}$ and the mechanical characterizations of the foaming samples were determined. The results showed that the additions can change the crystallization type from homogeneous to heterogeneous, increase the crystallization rate and shrink the size but increase the density of spherulites. Among the additions, $\mathrm{Q}[6]$ most significantly altered the crystallization properties. Scanning electron microscopy (SEM) images revealed that the PP foaming performance can be improved by $\mathrm{Zn}(\mathrm{Ac})_{2}$ addition at a lower temperature $\left(175^{\circ} \mathrm{C}\right)$; however, further increasing the temperature had an undesirable effect. Q[6] exhibited the optimum foaming improvement effect on $\mathrm{PP}$ in a wide temperature range $\left(175-195^{\circ} \mathrm{C}\right)$. Adding nanoparticles also enhanced the tensile properties, flexural strength and impact strength of foaming PP at low temperatures. However, with increasing temperature, the poor cell structure demonstrated undesirable effects in terms of tensile strength, flexural strength and impact strength.
\end{abstract}

Keywords: azodicarbonamide; crystallization; injection molding; mechanical properties; polypropylene.

\footnotetext{
*Corresponding authors: Li He, Department of Polymer Material and Engineering, College of Materials and Metallurgy, Guizhou University, Guiyang, Guizhou, China; and National Engineering Research Center for Compounding and Modification of Polymer Materials, Guiyang, Guizhou, China, e-mail: lihe@gzu.edu.cn; and Wei Gong, The Institute of Materials and Construction of Guizhou Normal University, Guiyang, Guizhou, China,

e-mail: gw20030501@163.com

Yuhui Zhou: Department of Polymer Material and Engineering, College of Materials and Metallurgy, Guizhou University, Guiyang, Guizhou, China; and The Institute of Chemistry and Chemical Industry of Guizhou University, Guiyang, Guizhou, China
}

\section{Introduction}

Polypropylene (PP) foams have developed rapidly in recent years. Because of their excellent properties, PP foams are widely used in many fields, such as in packaging materials, automobile parts and in thermal insulation. Therefore, the development of a simple method to prepare PP foams is challenging (1-3). Among all the foaming processes (either batch or continuous), microcellular injection molding employing chemical foaming agents is the most important commercial process due to its lower injection pressure, lower cost, shorter cycle times and less material used (4-6). However, microcellular injection molding performs poorly in technological applications, which mainly arise in the high processing temperatures for melting polymers and chemical blowing agents for decomposition (7).

During PP foaming with a chemical foaming agent, azodicarbonamide (AC) working in conjunction with in zinc salt is widely applied because of its high gas yield (8) and the catalysis of zinc salt (9). Zinc salt can significantly increase the decomposition rate and lower the decomposition temperature of $\mathrm{AC}(10,11)$, which means zinc salt makes polymer foaming at relative low temperature a possibility. Meanwhile, the melting strength increased at low temperature to suppress cell ripening and cell coalescence. In the PP foaming process employing the AC blowing agent system, cell nucleation can be effected by dispersed zinc salt in the polymer matrix (12). However, few studies have explored the effect of zinc salt on the foaming performance of polypropylene so far.

Adding nanofillers has demonstrated its effectiveness for improving PP foam morphology. Nanofiller not only reduces the nucleation energy barrier through the evolved interaction between nanofiller and polymer macromolecules, but also induces the crystallization of the polymer. That is, nanofillers can affect the foaming performance of the PP system through cell nucleation and changing its crystallization behavior (13). To the best of our knowledge, however, most of recent studies have focused on inorganic particles, such as clay (14), nano-calcium carbonate (15) and so on, little attention has been given to functional 
organic nanoparticles, which can also be used as effective nucleating agent and functional reinforcement (16).

In our previous studies, cucurbit[6]uril (Q[6]) (17) with relative low content (1.0 wt \%) was successfully used to improve PP microcellular foaming behavior in the presence of $\mathrm{AC}$ as a chemical blowing agent. After that, a novel inorganic-organic nucleating agent (18) supramolecular compound Zn@Q[6] was synthesized by Q[6] and zinc acetate $\left[\mathrm{Zn}(\mathrm{Ac})_{2}\right]$ through a chemical method. The underlying mechanisms of improved cell morphology were discussed using thermal and rheological analyses, but not involving the properties of foamed materials. In this current paper, we utilized $\mathrm{Zn}(\mathrm{Ac})_{2}$ as an activator for the chemical blowing agent AC. The microcellular PP structures composited with Zn(Ac), Q[6], Q[6]@Zn and a mixture of $\mathrm{Zn}(\mathrm{Ac})_{2}$ and $\mathrm{Q}[6]$ were prepared through an injection molding process. Considering the effect differences of organic and inorganic nucleation agents on the foaming performance of PP, we prepared the foaming samples at different temperatures. The crystallization behavior of the PP composites was then systematically studied. The cell morphology was compared, and finally, the mechanical properties of the foamed samples were comprehensively studied. We aimed to evaluate the comprehensive property of PP foams with the new nucleation agent for further applications in future.

\section{Experimental}

\subsection{Materials}

Chemicals, such as $\mathrm{Zn}(\mathrm{Ac})_{2}$ and $\mathrm{HCl}$ (Chongqing Co., China) were of reagent grade and used without further purification. Q[6] was prepared according to the previously reported procedure in our laboratory $(19,20)$. PP was purchased from SINOPEC Co. (China). The blowing agent AC with gas production of about $220 \mathrm{ml} / \mathrm{g}$ was obtained from Hanhong Co. (China).

\subsection{Preparation of Zn@Q[6] supramolecular compound}

$\mathrm{Zn}(\mathrm{Ac})_{2}$ and $\mathrm{Q}[6]$ (equivalence ratio was 5:1) was first dissolved in $\mathrm{HCl}(3 \mathrm{M})$, respectively. Next, the Q[6] solution was slowly added into $\mathrm{Zn}(\mathrm{Ac})_{2}$, solution accompanied by stirring at $250 \mathrm{rpm}$. Then, the reaction solution was placed at room temperature to ensure the slow evaporation of the volatiles. Colorless crystals were finally obtained from the reaction solution within 1 week.

\subsection{Preparation of PP composites}

PP composites were prepared with 1.0 wt $\%$ of $\mathrm{Zn@Q[6],}$ $\mathrm{Q}[6], \mathrm{Zn}(\mathrm{Ac})_{2}$ or a mixture of $\mathrm{Zn}(\mathrm{Ac})_{2}$ and $\mathrm{Q}[6]$ (weight ratio of 1:1) through a twin-screw extruder (Ruiya SE40A, Nangjing, China) with an increasing extrusion temperature profile $\left(175-195^{\circ} \mathrm{C}\right)$. Thereafter they were coded as $\mathrm{P}(\mathrm{Zn} @ \mathrm{Q}[6]), \mathrm{PQ}, \mathrm{PZn}$ and $\mathrm{P}(\mathrm{Q}[6]+\mathrm{Zn})$, respectively.

\subsection{Injection molding foaming}

The foaming samples were fabricated through a microcellular injection foaming molding machine (Nangjing Ruiya, China) equipped with a volume-adjustable cavity. The temperature from hopper to nozzle was set from 175 to $195^{\circ} \mathrm{C}$ with a gradient of $5^{\circ} \mathrm{C}$. The sample expansion ratio was controlled by a cavity thickness expanding from $3.5 \mathrm{~mm}$ to $4.0 \mathrm{~mm}$. The gas $\left(\mathrm{N}_{2}\right)$ content was $1 \%$, determined by the gas production of the $\mathrm{AC}$ percentage.

\subsection{Characterization}

A differential scanning calorimetry (DSC, Netzsch 499C, Germany) experiment was performed under a nitrogen atmosphere. Every sample was approximate $5 \mathrm{mg}$ with an aluminum crucible. The samples were first heated to eliminate the thermal history at a rate of $10^{\circ} \mathrm{C} / \mathrm{min}$ from 35 to $200^{\circ} \mathrm{C}$. Then, the samples were cooled to $35^{\circ} \mathrm{C}$ and finally reheated to $200^{\circ} \mathrm{C}$ at the same temperature variation rate.

Wide-angle X-ray diffraction (WAXD, Bruker D8, Germany) and polarized optical microscopy (POM; PM6000, Nanjing, China) were conducted to show the crystallization properties of the composites. The samples were prepared by hot pressing polymer into a $50 \mu \mathrm{m}$-thick film at $230^{\circ} \mathrm{C}$, and then crystallized completely at $110^{\circ} \mathrm{C}$.

Scanning electron microscope (SEM, KYKY-2800B) (Beijing Zhongke, China) was conducted to show the morphologies of the foamed samples. The samples were freeze fractured in liquid nitrogen and sputter-coated with gold, they were observed with an accelerating voltage of $25.0 \mathrm{kV}$. The cell sizes determined from the SEM micrographs were calculated via image analysis (Image-Pro Plus software). The cell density was calculated from the equation:

$$
N_{\mathrm{o}}=\left[\frac{\mathrm{n} M^{2}}{A}\right]^{3 / 2}\left[\frac{\rho}{\rho_{\mathrm{f}}}\right]
$$

where $N_{0}$ is the cell density (cells/ $\mathrm{cm}^{3}$ ), $\mathrm{n}$ is the number of cells on the SEM micrograph, $M$ is the magnification factor and $A$ is the area of the micrograph $\left(\mathrm{cm}^{2}\right)$. The densities of 
unfoamed $(\rho)$ and foamed $\left(\rho_{\mathrm{f}}\right)$ samples were measured in accordance with ASTM D792.

Mechanical property tests were performed according to ASTM D638-10 for tensile test, ASTM D790-10 for threepoint flexural test and ASTM D256-10 for Izod notched impact strength test, respectively. Five measurements per sample were taken to check the repeatability of data.

\section{Results and discussion}

\subsection{Crystallization behavior of PP composites}

Figure 1 shows the non-isothermal crystallization behavior of PP and PP composites measured by DSC. The corresponding crystallization parameters are listed in Table 1, where $T_{\mathrm{p}}$ is the temperature of crystallization peak and $T_{\mathrm{c}}$ is the temperature at the onset of crystallization. The crystallization rate can be characterized by $\left(T_{\mathrm{c}}-T_{\mathrm{p}}\right)$, that is, high $\left(T_{\mathrm{c}}-T_{\mathrm{p}}\right)$ value results in low total crystallization rate under the same crystallization conditions. Nonisothermal crystallization kinetics were analyzed via the Jeziorny method (21), the half crystallization time $\left(t_{1 / 2}\right)$, the Avrami exponent (n) and the corrected crystallization rate constant $\left(Z_{c}\right)$ were calculated (Table 1 ). As shown, the

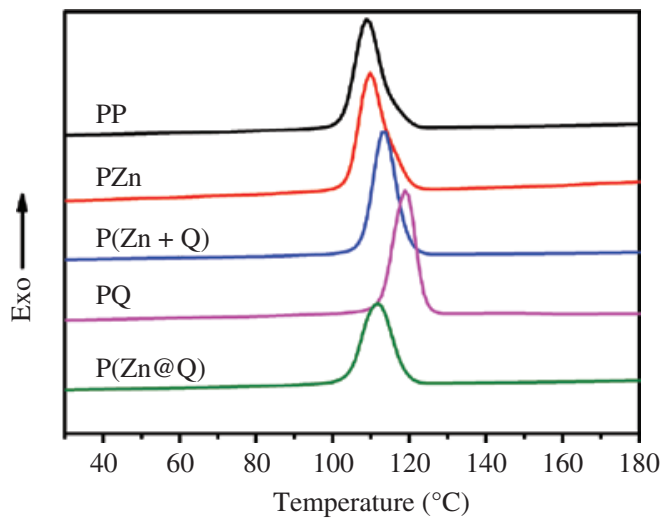

Figure 1: Curves of crystallization of PP and PP composites.

Table 1: Crystallization kinetic parameters of PP and PP composites.

\begin{tabular}{lrrrrrr}
\hline Sample & $\boldsymbol{T}_{\mathrm{c}}\left({ }^{\circ} \mathrm{C}\right)$ & $\boldsymbol{T}_{\mathrm{p}}\left({ }^{\circ} \mathrm{C}\right)$ & $\boldsymbol{T}_{\mathrm{c}}-\boldsymbol{T}_{\mathrm{p}}\left({ }^{\circ} \mathrm{C}\right)$ & $\boldsymbol{t}_{1 / 2}(\min )$ & $\mathrm{n}$ & $\boldsymbol{Z}_{\mathrm{c}}$ \\
\hline $\mathrm{PP}$ & 123.5 & 109.0 & 14.5 & 1.41 & 2.49 & 0.84 \\
$\mathrm{PZn}$ & 122.9 & 109.7 & 13.2 & 1.36 & 2.80 & 0.95 \\
$\mathrm{P}(\mathrm{Zn}+\mathrm{Q})$ & 124.3 & 113.3 & 11.0 & 1.35 & 3.10 & 0.99 \\
$\mathrm{PQ}$ & 128.3 & 119.2 & 9.1 & 1.13 & 3.43 & 1.25 \\
$\mathrm{P}(\mathrm{Zn} @ Q)$ & 122.9 & 111.8 & 11.1 & 1.31 & 2.83 & 1.06 \\
\hline
\end{tabular}

$T_{\mathrm{p}}$ and $T_{\mathrm{c}}$ were improved in the composites modified by the additions. The values for $\left(T_{\mathrm{c}}-T_{\mathrm{p}}\right)$ of the PP composites decreased because of the heterogeneous nucleation of the additions. For example, when Q[6] was added, the value of $\left(T_{c}-T_{p}\right)$ decreased from 14.5 of pure PP to 9.1 of PQ. This observation indicates that the crystallization rate of $\mathrm{PP}$ composites increased noticeably. For PP composites, $t_{1 / 2}$ was smaller than that of PP (Table 1). This result means that the half crystallization time of PP was shortened by adding $\mathrm{Q}[6], \mathrm{Zn}(\mathrm{Ac})_{2}$ and their compounds, with $\mathrm{Q}[6]$ being the most effective. Greater values of $\mathrm{n}$ and $Z_{\mathrm{c}}$ can be observed in PP composites compared with those of PP under the non-isothermal conditions, which implies that the nucleation and growth mode of the crystallization for PP composites were altered, and the completion of crystallization was accelerated.

\subsection{Melting behavior of PP composites}

The melting curves of PP and the PP composites are shown in Figure 2. Compared with pure PP, almost no change can be observed in the melting temperature of PP composites, which means the melting behavior did not change considerably with the addition of $\mathrm{Q}[6], \mathrm{Zn}(\mathrm{Ac})_{2}$ and their two compounds. The crystallinity of the system can be characterized by the melting peak area, namely, a large peak area results in a high crystallinity. Notably, the melting peak area of the PP composites shrank relative to that of the pure PP. This result suggests that the additions decreased the crystallinity.

\subsection{Crystal structure of PP composites}

For PP, three kinds of crystal forms exist, that is, $\alpha$-form, $\beta$-form and $\gamma$-form, which can be distinguished by

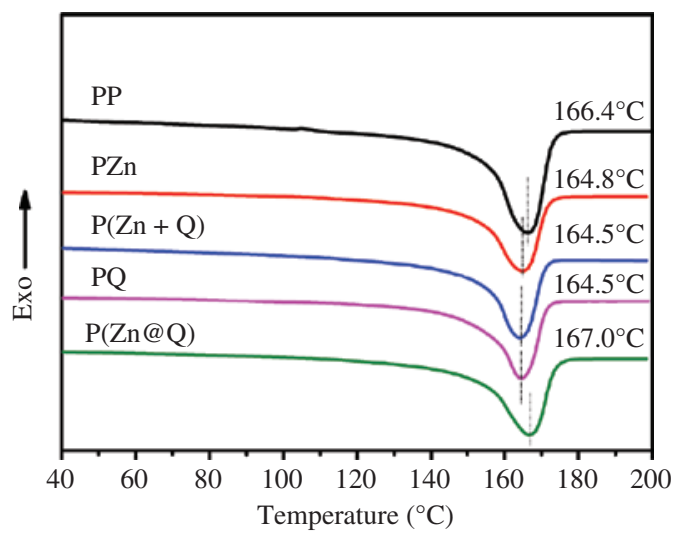

Figure 2: Melting curves of PP and PP composites. 


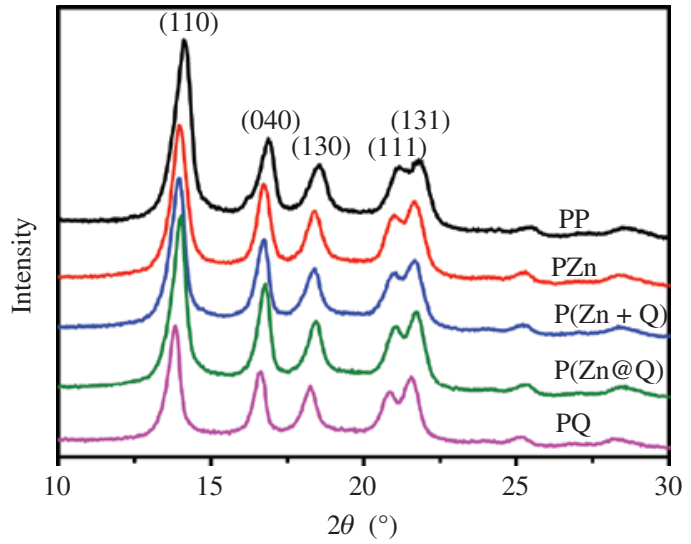

Figure 3: XRD patterns of PP and PP composites.

WAXD. Figure 3 presents the WAXD curves of PP and the PP composites. As shown, PP and PP composites exhibited similar diffraction curves. The diffraction angles

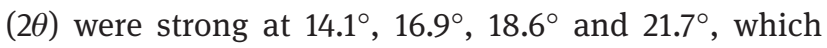
correspond to the $\alpha$-form monoclinic crystal faces of (110), (040) and (130) and the superposed crystal faces of $(111) /(131)$, respectively. Given the low percentage of fillers, intense peaks of the fillers did not appear. According to Chen et al. (22), the $2 \theta$ located at $16^{\circ}$ and $21^{\circ}$ is for the $\beta$-form, whereas that of the $\gamma$-form is located at $20.3^{\circ}$. However, the diffraction peaks corresponding to the $\beta$-form and $\gamma$-form crystals were not observed, which indicates that PP is a typical $\alpha$-form crystal that does not change with the addition of $\mathrm{Q}[6], \mathrm{Zn}(\mathrm{Ac})_{2}$ and their two compounds.

The XRD pattern peak separation method was applied to calculate the crystallinity $\left(X_{c}\right)$ of each system and the corresponding results are listed in Table 2 . The value of crystallinity decreased with the addition of fillers in PP which can be attributed to the heterogeneous nucleation effect induced by the additions. Such an effect destroys the regularity of PP spherulites and diminishes crystallization. Moreover, the molecular chains may be hampered by the fillers, and the formation of orderly crystals may be delayed. A similar observation was reported when clay was used (23).

Table 2: Crystallinities of PP and PP composites.

\begin{tabular}{lc}
\hline Sample & $\boldsymbol{X}_{\mathrm{c}}(\%)$ \\
\hline PP & 68.7 \\
PZn & 66.4 \\
P(Zn+Q) & 64.5 \\
PQ & 55.1 \\
P(Zn@Q) & 59.8 \\
\hline
\end{tabular}

\subsection{Crystal morphology of PP composites}

POM was conducted to show the crystallization properties of the samples, the micrographs are shown in Figure 4. As we can see, PP generally crystallizes into an isotropic state during melt crystallization, pure PP shows a spherulite with a large size, regular structure and clear boundaries. Adding $\mathrm{Q}[6], \mathrm{Zn}(\mathrm{Ac})_{2}$ and their two compounds significantly decreased the size, increased the number of PP spherulites, destroyed the integrity and blurred the boundaries of such structures. The size and density of spherulites of $\mathrm{PQ}$ were the most altered amongst those of the systems tested (Figure $4 \mathrm{~B}-\mathrm{G}$ ). For pure PP, the crystallization process involves homogeneous nucleation and the amount of nuclei is relatively limited. As a result, the spherulite of pure PP can grow extremely large under sufficient undercooling. Whereas, the nucleation of the PP composites system can be induced by the heterogeneous nucleation sites provided by the nanofillers. Then, the molecular chains around the nuclei rearrange to form small circular spherulites. Ji et al. (24) proposed that smaller PLA spherulites were observed attributed to the heterogeneous nucleation effect provided by nanosilica. Li et al. (25) also found that the PP composites have smaller size and more uniform distributions of spherulites. Therefore, the introduction of Q[6], $\mathrm{Zn}(\mathrm{Ac})_{2}$ and their two compounds were proved to obviously improve the behavior of PP crystallization, such as the crystallization rate, crystallinity and micrographs, which may improve the foaming performance of PP composites in the injection process.

\subsection{Foaming performance of PP composites}

Figure 5 showed the SEM micrographs of the fracture surface, and Figure 6 illustrated the corresponding cell sizes and density. As shown, PP foam exhibited poor cell morphology with a non-uniform distribution at low temperature and big cell sizes at high temperature. With the addition of $\mathrm{Zn}(\mathrm{Ac})_{2}$, the cell distribution of PP improved at $175^{\circ} \mathrm{C}$ compared with that of pure PP. This effect may be attributed to the activated decomposition of $\mathrm{AC}$ and the cell nucleation effect of $\mathrm{Zn}(\mathrm{Ac})_{2}(26,27)$. Unfortunately, with increasing temperature, the average cell size increased significantly, even more so than that of pure PP. This effect occurred because the melt strength of PP decreased with increasing temperature, and the presence of $\mathrm{Zn}(\mathrm{Ac})_{2}$ exacerbated this change. The cell morphology of the $\mathrm{P}(\mathrm{Zn}+\mathrm{Q}[6])$ system showed the same tendency as that of PZn. However, the cell morphology of the $\mathrm{P}(\mathrm{Zn}+\mathrm{Q}[6])$ 

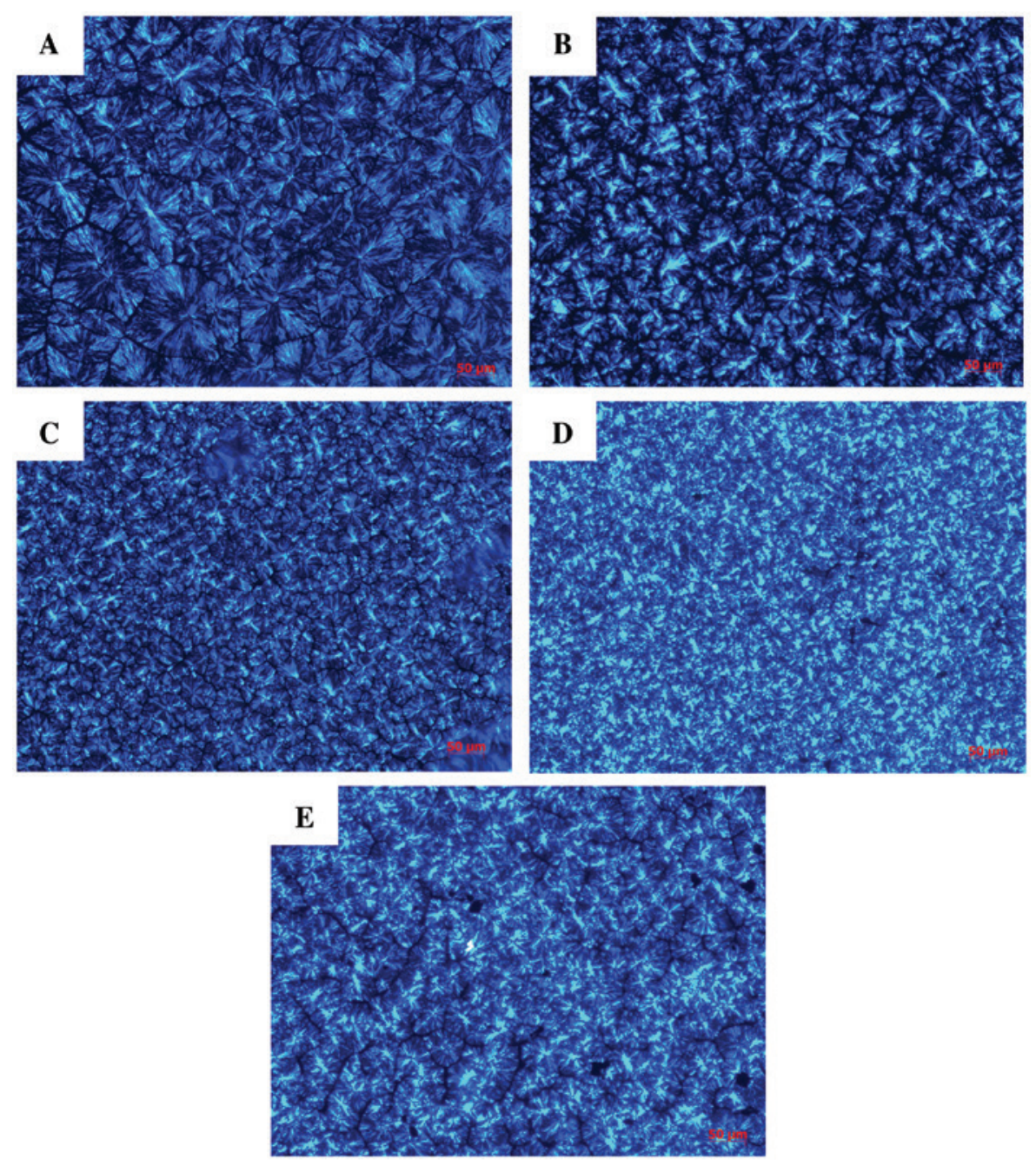

Figure 4: $P O M$ micrographs of $P P(A)$ and PP composites: (B) PZn; (C) $P(Z n+Q)$; (D) PQ and (E) $P(Z n @ Q)$.

system with a mass ratio of 1:1 for Q[6] and $\mathrm{Zn}(\mathrm{Ac})_{2}$ was enhanced as compared with that of PZn at different foaming temperatures. This phenomenon indicated that $\mathrm{Q}[6]$ has better nucleation efficiency relative to that of $\mathrm{Zn}(\mathrm{Ac})$. The $\mathrm{P}(\mathrm{Zn}+\mathrm{Q}[6])$ foaming temperature range showed no advantage, compared with that of pure PP except for $175^{\circ} \mathrm{C}$. We concluded from the above results that the PP foam can be improved by $\mathrm{Zn}(\mathrm{Ac})_{2}$ at a low temperature, but increasing the temperature had a further undesired effect.

By adding Zn@Q[6] to PP, the cell morphology was improved in a relatively wide temperature range $\left(180-195^{\circ} \mathrm{C}\right)$. However, the experimental system exhibited no superiority at $175^{\circ} \mathrm{C}$, because AC cannot be catalyzed at lower temperature without $\mathrm{Zn}(\mathrm{Ac})_{2}$. When $\mathrm{Q}[6]$ was added to PP, the cell morphology was significantly improved within the temperature range of $175-195^{\circ} \mathrm{C}$. The optimum cell size of $\mathrm{PQ}$ was $24.5 \mu \mathrm{m}$ at $185^{\circ} \mathrm{C}$, and the relative cell density was $1.9 \times 10^{7}$ cells $/ \mathrm{cm}^{3}$. These results imply that the cell structure can be improved by the addition of the $\mathrm{Q}[6]$ particles as the nucleating agent. $\mathrm{Q}[6]$ manifested the best cell nucleation effect relative to those of $\mathrm{Zn}(\mathrm{Ac})_{2}$ and $\mathrm{Zn@Q}[6]$, and such performance can be attributed to the unique macrocyclic structure and polarizable chemical property of Q[6]. These special characteristics endowed the particles with a high nucleation efficiency.

\subsection{Mechanical properties}

The tensile properties of neat PP and PP composites are shown in Figure 7 compared with neat PP, the tensile strength for the PP composites increased at $175^{\circ} \mathrm{C}$. Meanwhile, the tensile strength for $\mathrm{PZn}$ and $\mathrm{P}(\mathrm{Zn}+\mathrm{Q})$ decreased lower than that of pure PP with the temperature increasing beyond $180^{\circ} \mathrm{C}$. Concurrently, the increase in tensile strength was greater in the $\mathrm{PQ}$ and $\mathrm{P}(\mathrm{Zn} @ \mathrm{Q})$ than in the 

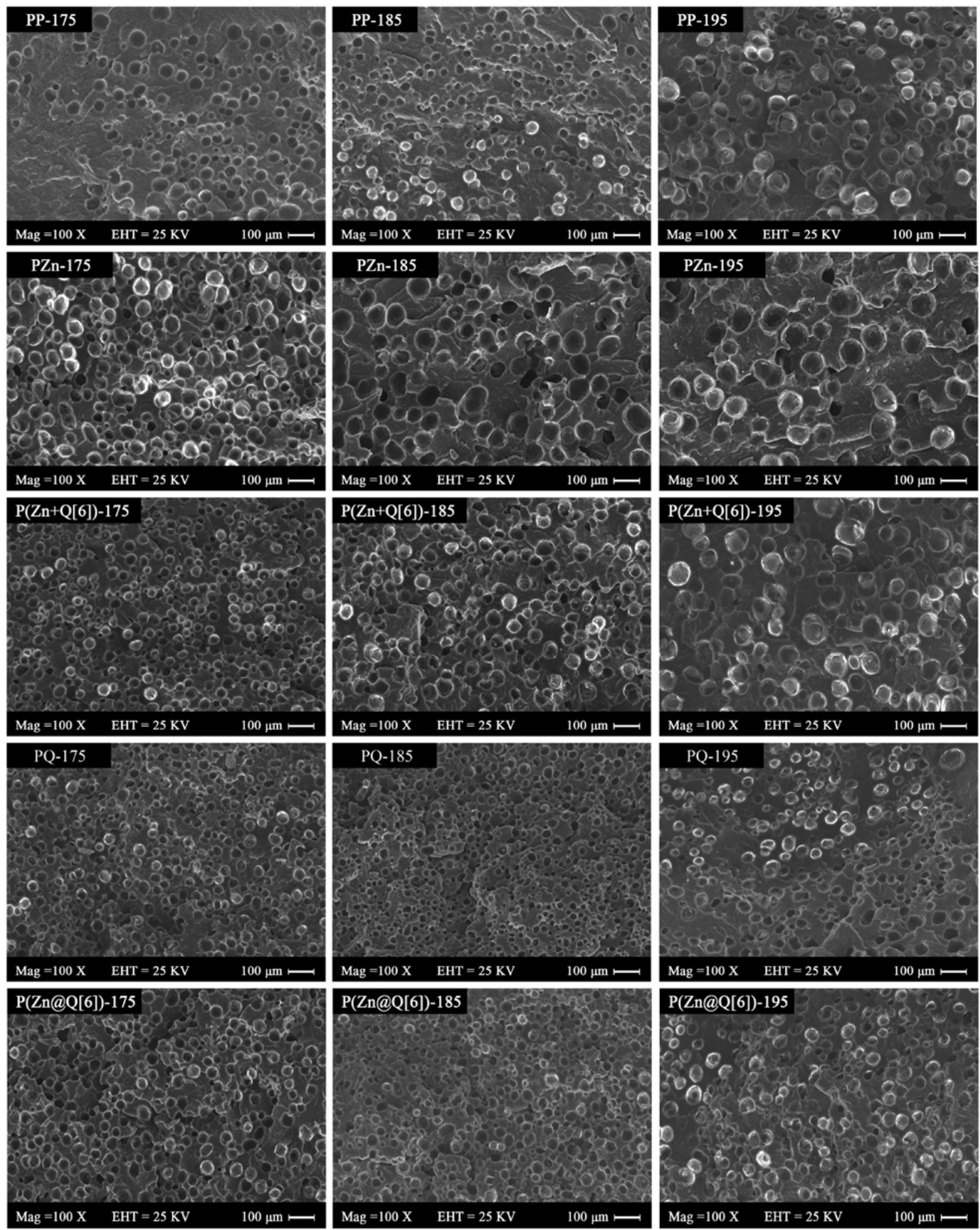

Figure 5: SEM images of PP and PP composite foams.

pure PP. As shown, the cell size and density varied with increasing temperature. The composite systems exhibited similar cell sizes and densities at $175^{\circ} \mathrm{C}$. With the temperature increasing beyond $180^{\circ} \mathrm{C}$, the cell sizes of $P Z n$ and $P(Z n+Q)$ increased, whereas those of $P Q$ and $\mathrm{P}(\mathrm{Zn} @ Q)$ decreased relative to that of pure PP. The fillers 
A

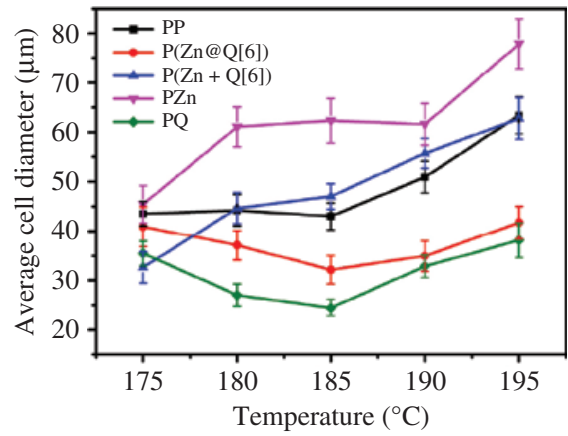

B

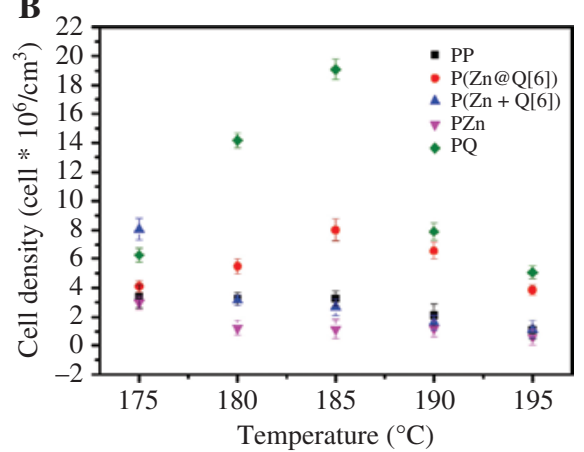

Figure 6: Average cell diameter (A) and cell density (B) of foamed PP and PP composite.
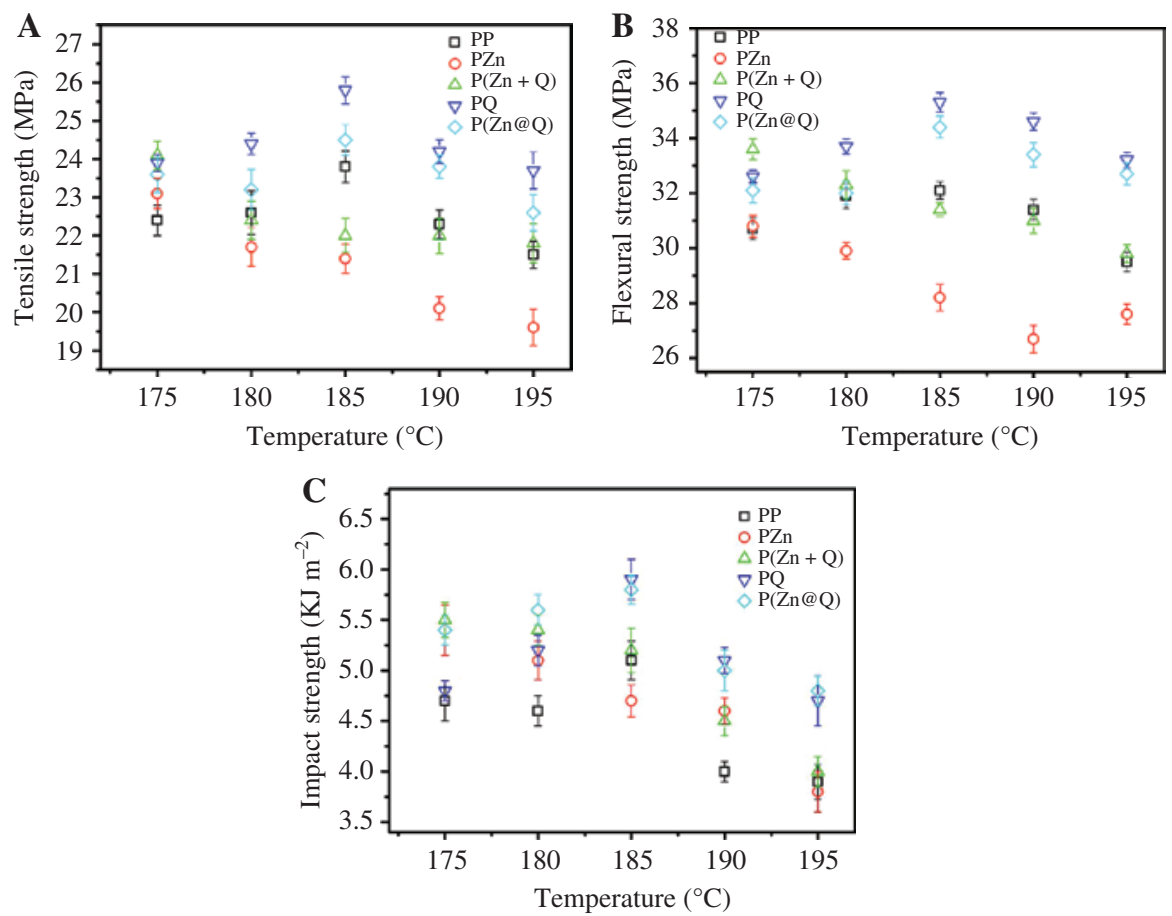

Figure 7: Tensile strength (A), flexural strength (B) and impact strength (C) for foamed samples.

added to PP can absorb the polymer matrix on its surface and reduce the ability of the foams to deform and stretch (28). However, during tensile testing, large cells were prone to stretch from circular shapes to elliptical ones and then collapsed upon fracturing. Accordingly, the decreased cell size and increased cell density diminished the ability of the cells to deform and further stretch with the applied tensile stress.

The flexural strength versus temperature curves of all the samples are shown in Figure 7B. The flexural strength increased by adding particles to the PP polymer, and this tendency is similar to that of the tensile strength at $175^{\circ} \mathrm{C}$. The phenomena of the increased interface interaction between the matrix and particles ultimately reduced the lower polymeric chain mobility and increased the material rigidity. With the increasing temperature, however, the cell morphologies of $\mathrm{PZn}$ and $\mathrm{P}(\mathrm{Zn}+\mathrm{Q})$ gradually became inferior over that of pure PP. Therefore, the voids in the foams act as stress concentrators that reduce the flexural strength.

The impact strength values for various samples were illustrated in Figure 7C. As shown, adding nanoparticles into the PP matrix improved the impact strength at low temperatures $\left(175-180^{\circ} \mathrm{C}\right)$. These improvements originated from the advantages of the nanoparticles in terms of tensile and flexural properties. During impact testing, rigid particles provide increased toughness, improved fatigue life and enhanced energy absorption. Meanwhile, 
small cells demonstrated advantages in promoting plastic deformation, cell collapse and absorbing impact energy during the fracture process. Nevertheless, poor cell structure retrogressed at high temperatures $\left(185-195^{\circ} \mathrm{C}\right)$. This behavior indicated that the effect was undesirable in terms of tensile strength, flexural strength and impact strength.

\section{Conclusions}

In this paper, microcellular PP composites with $\mathrm{Zn}(\mathrm{Ac})_{2}$, $\mathrm{Q}[6], \mathrm{Q}[6] @ Z n$ or a mixture of $\mathrm{Zn}(\mathrm{Ac})_{2}$ and $\mathrm{Q}[6]$ were prepared through injection molding in the presence of the chemical blowing agent AC. We found that the crystallization of the PP composites accelerated, but the crystallinity values decreased. In addition, the size of PP spherulites decreased, but their density increased significantly. These crystallization behavioral changes of PP may be attributed to the heterogeneous nucleation effect induced by the additions. The results showed that the PP composite foaming performance can be improved by $\mathrm{Zn}(\mathrm{Ac})_{2}$ at a low temperature $\left(175^{\circ} \mathrm{C}\right)$, whereas increasing the temperature further disfavored this effect. Q[6] exhibited the optimum foaming improvement effect of $\mathrm{PP}$ in a wide temperature range $\left(175-195^{\circ} \mathrm{C}\right)$. Adding nanoparticles into the foaming PP matrix enhanced the tensile properties, flexural strength and impact strength at low temperatures while the fillers act as concentrators. However, the cell morphology retrogressed at high temperatures, which indicated that the effect is undesirable in terms of tensile strength, flexural strength and impact strength.

Acknowledgments: Financial supports from Guizhou science and technology cooperation platform talents ([2017]5788); Excellent Youth and Science \& Technology Talent Foundation of Guizhou Province ([2015]29); the Hundred Talents Project of Guizhou Province ([2016]5673); The national nature fund of China (51503047).

\section{References}

1. Gao W, Zheng Y, Shen J, Guo S. Electrical properties of polypropylene-based composites controlled by multilayered distribution of conductive particles. ACS Appl Mater Interfaces. 2015;7: 1541-9.

2. Fasihi M, Targhi AA, Bayat $\mathrm{H}$. The simultaneous effect of nucleating and blowing agents on the cellular structure of polypropylene foamed via the extrusion process. E-ploymers. 2016;16:235-41.
3. Alkan Ü, Karabul Y, Bulgurcuoğlu AE, Kılıç M, Özdemir ZG, İçelli O. Polypropylene/basalt thick film composites: structural, mechanical and dielectric properties. E-ploymers. 2017;17:41725.

4. Zhai WT, Kuboki T, Wang L, Park CB. Cell structure evolution and the crystallization behavior of polypropylene/clay nanocomposites foams blown in continuous extrusion. Ind Eng Chem Res. 2010;49:9834-45.

5. Wang K, Wu F, Zhai W, Zheng W. Effect of polytetrafluoroethylene on the foaming behaviors of linear polypropylene in continuous extrusion. J Appl Polym Sci. 2013;129:2253-60.

6. Mantaranon N, Chirachanchai S. Polyoxymethylene foam: from an investigation of key factors related to porous morphologies and microstructure to the optimization of foam properties. Polymer. 2016;96:54-62.

7. Colton JS. The nucleation of microcellular foams in semicrystalline thermoplastics. Mater Manuf Process. 1989;4:253-62.

8. Heck LR. A review of commercially used chemical foaming agents for thermoplastic foams. J Vinyl Add Tech. 1998;4:113-6.

9. Hurnik H. Chemical blowing agents in plastics additives handbook, Chapter 13. In: Zweifel H, editor, 5th ed. Germany: Hanser Publishers; 2001. $699 \mathrm{p}$.

10. Soares FA, Nachtigall SMB. Effect of chemical and physical foaming additives on the properties of PP/wood flour composites. Polym Test. 2013;32:640-6.

11. Reyes-Labarta JA, Marcilla A. Thermal treatment and degradation of cross-linked ethylene vinyl acetate-polyethyleneazodicarbonamide-ZnO foams: complete kinetic modeling and analysis. Ind Eng Chem Res. 2012;51:9515-30.

12. Zhai WT, Yu J, Wu LC, Ma WM, He JS. Heterogeneous nucleation uniformizing cell size distribution in microcellular nanocomposites foams. Polymer. 2006;47:7580-9.

13. Kalaitzidou K, Fukushima H, Askeland P, Drzal LT. The nucleating effect of exfoliated graphite nanoplatelets and their influence on the crystal structure and electrical conductivity of polypropylene nanocomposites. J Mater Sci. 2008;43:2895-907.

14. Zheng WG, Lee YH, Park CB. Use of nanoparticles for improving the foaming behaviors of linear PP. J Appl Polym Sci. 2010;117:2972-9.

15. Huang HX, Wang JK. Improving polypropylene microcellular foaming through blending and the addition of nano-calcium carbonate. J Appl Polym Sci. 2007;106:505-13.

16. Zou CJ, Gu T, Xiao PF, Ge TT, Wang M, Wang K. Experimental study of cucurbit[7]uril derivatives modified acrylamide polymer for enhanced oil recovery. Ind Eng Chem Res. 2014;53:7570-8.

17. Zhou YH, Gong W, He L. Application of a novel organic nucleating agent: cucurbit[6]uril to improve polypropylene injection foaming behavior and their physical properties. J Appl Polym Sci. 2017;134:44538-46.

18. Zhou YH, Wang LJ, Xiao X, Gong W, He L. Preparation of a novel inorganic-organic nucleating agent and its effect on the foaming behavior of polypropylene. Inorg Organomet Polym. 2017;27:1538-45.

19. Day A, Arnold AP, Blanch RJ, Snushall B. Controlling factors in the synthesis of cucurbituril and its homologues. J Org Chem. 2001;66:8094-100.

20. Wu F, Wu, LH, Xiao X, Zhang YQ, Xue SF, Tao Z, Day A. Locating the cyclopentano cousins of the cucurbit[n]uril family. J Org Chem. 2012;77:606-11. 
21. Jeziorny A. Parameters characterizing the kinetics of the nonisothermal crystallization of poly (ethylene terephthalate) determined by DSC. Polymer. 1978;19:1142-4.

22. Chen J, Sun XF, Turng LS, Zhao L, Liu T, Yuan WK. Investigation of crystallization behavior of solid and microcellular injection molded polypropylene/nano-calcium carbonate composites using carbon dioxide as a blowing agent. J Cell Plast. 2013;49:459-475.

23. Shieh YT, Lai JG, Tang WL, Yang CH, Wang TL. Supercritical $\mathrm{CO}_{2}$ intercalation of polycaprolactone in layered silicates. J Supercrit Fluids. 2009;9:385-93.

24. Ji GY, Zhai WT, Lin DP, Ren Q, Zheng WG, Jung DW. Microcellular foaming of poly(lactic acid)/silica nanocomposites in compressed $\mathrm{CO}_{2}$ : critical influence of crystallite size on cell morphology and foam expansion. Ind Eng Chem Res. 2013;52:6390-8.
25. Li ZS, Chen MJ, Ma WH. Polypropylene/hydroxyl-multiwall carbon nanotubes composites: crystallization behavior, mechanical properties, and foaming performance. J Mater Sci. 2016;51:4566-79.

26. Reyes-Labarta JA, Marcilla A. Kinetic study of the decompositions involved in the thermal degradation of commercial azodicarbonamide. J Appl Polym Sci. 2008;107:339-46.

27. Petchwattana N, Covavisaruch S. Influences of particle sizes and contents of chemical blowing agents on foaming wood plastic composites prepared from poly(vinyl chloride) and rice hull. Mater Des. 2011;32:2844-50.

28. Sun XF, Kharbas H, Peng J, Turng LS. A novel method of producing lightweight microcellular injection molded parts with improved ductility and toughness. Polymer. 2015;56:102-10. 